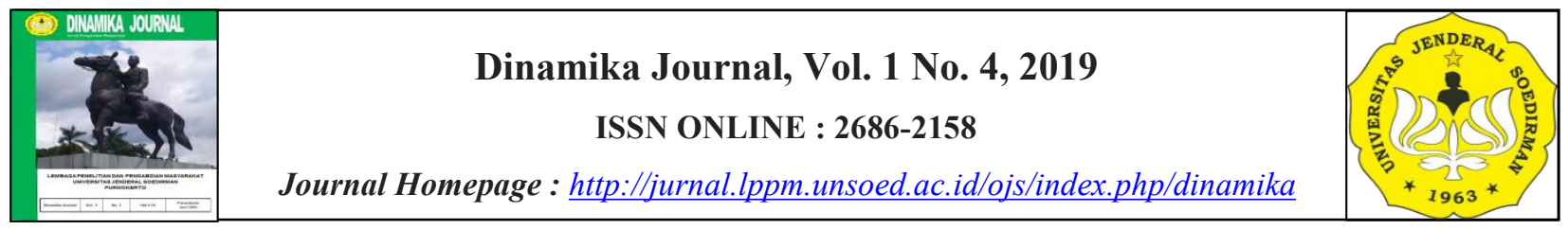

\title{
UPAYA PEMBINAAN KETAHANAN SOSIO-BUDAYA REMAJA MELALUI MODEL MONOLINGUISTIK PRANCIS DALAM PEMBELAJARAN BAHASA ASING DI SMA NEGERI 4 PURWOKERTO
}

\author{
${ }^{1}$ Tri Asiati ${ }^{1, *}$, Monika Herliana1), Rizki Utami' ${ }^{1)}$ \\ ${ }^{1}$ Fakultas Ilmu Budaya, Universitas Jenderal Soedirman, Purwokerto, Indonesia \\ *Corresponding author: asiatitri@yahoo.com
}

Received 10 November 2019; Accepted 1 Desember 2019; Available online 4 Desember 2019

\begin{abstract}
Abstrak
Program Pemberdayaan Masyarakat ini secara umum bertujuan untuk menerapkan hasil riset penelitian, sedangkan tujuan khususnya adalah: (1)mengarahkan sikap dan perilaku remaja sesuai dengan nilai-nilai kearifan lokal, (2)menanamkan kecintaan remaja terhadap bahasa dan budaya nasional, (3)menanamkan kecintaan pada bahasa dan budaya daerah, (4)menamkan sikap menghormati dan toleransi terhadap bahasa dan budaya lain, (5)menanamkan universalitas dan kemanunggalan bahasa nasional, dan (6)menumbuhkan kreativitas berbahasa sebagai wujud ketahanan sosio-budaya remaja. Adapun program kegiatan ini dilaksanakan di SMA Negeri 4 Purwokerto sebagai bentuk implementasi riset dengan judul "Adaptasi Model Monolinguistik Prancis dan Eksistensi Lembaga Budaya dalam Meningkatkan Ketahanan Lingua Franka". Pada pelaksanaannya diterapkan metode: tanya jawab, diskusi, latihan, dan praktek. Sementara itu indikator keberhasilannya diukur melalui evaluasi pre-test dan post-test untuk mengetahui efektivitas model monolinguistik Prancis dalam membina ketahanan sosio-budaya remaja.
\end{abstract}

Kata kunci : ketahanan, monolinguistik, pembinaan, prancis, dan sosio-budaya

\begin{abstract}
This program generally aims to apply the result of research while the specific objectives are : (1) directing the attitudes and behaviour of teenagers in accordance with values of local wisdom, (2) instilling a sense of love for national language and culture, (3) instilling a sense of love for regional languages and cultures, (4) inculcating the respect and the tolerance for other languages and other cultures, (5) instilling the universality and the unity of national languages, and (6) fostering the language creativity as a form of teenagers socio-cultural resilience where located at SMA Negeri 4 Purwokerto as a form of applying research results with the title "Adaptasi Model Monolinguistik Prancis dan Eksistensi Lembaga Budaya dalam Meningkatkan Ketahanan Lingua Franka" In this case, the methods used are: presentation, discussion, and practice. Finally, the indicators of success are measured through evaluations with pre-test and post-test in order to determine the effectiveness of the French monolinguistic.
\end{abstract}

Keywords : apply, france, monolinguistic, resilence, and socio-culture 


\section{PENDAHULUAN}

Dahulu kecerdasan seseorang diukur berdasarkan ukuran Intelligence Quotient atau IQ. Konsep ini diciptakan oleh Francis Galton pada tahun 1890-an. Selang 93 tahun kemudian Howard Gardner seorang spikolog dan ahli pendidikan merumuskan teori Multiple Intelligens atau kecerdasan majemuk (Rindang,2019). Menurutnya kecerdasan manusia tidaklah tunggal, tetapi jamak, yangmana terdiri atas kecerdasan: matematis, linguistik, musikal, visual, kinestetis, naturalis, interpersonal, dan spiritual. Alhasil fokus kecerdasan, tidak lagi pada logika matematika sebagaimana umumnya dipahami oleh masyarakat, namun bersifat majemuk.

Berpijak dari kecerdasan majemuk, kecerdasan lingual menjadi salah satu sorotan publik saat ini. Hal ini dilatarbelakangi oleh adanya korelasi lurus antara kecerdasan lingual dengan kecerdasan emosional. Ditambah lagi dalam ranah bahasa muncul terminologi bilingual sepertihalnya fakta linguistik Indonesia yang terkait dengan eksistensi bahasa daerah dan bahasa nasional. Kemudian, fakta baru mengemukakan mengenai konsep multilingual sebagai fenomena populer dengan orientasi pada bahasa asing sebagai aspek fundamental dalam pergaulan internasional. Secara umum penguasaan bahasa asing di Indonesia didapat melalui proses formal maupun informal sebagaimana dijelaskan oleh Anak UI.Com (2015) dalam blognya mencakup tren pembelajaran bahasa Asing, seperti: bahasa Arab, bahasa Inggris, bahasa Jepang, bahasa Mandarin, dan bahasa Prancis dengan ragam manfaat selain aspek kebahasaan dan kebudayaan. Jessica (2007) menjelaskan manfaat mempelajari bahasa asing diluar jalur kebahasan dan kebudayaan, meliputi: (1) perkembangan otak, (2) peningkatan fokus dan orientasi, (3) peningkatan kecerdasan emosional, dan (4) peningkatan kekuatan jaringan otak. Oleh sebab itu, selain beradaptasi terhadap situasi global, kecerdasaan multilingual terbukti berkontribusi dalam meningkatkan kualitas hidup penuturnya.

Perkembangan kecerdasan multilingual sebagai fenomena linguistik modern disebabkan oleh keterbukaan akses dan mendorong bahasa asing sebagai aspek utama generasi muda Indonesia. Hal ini dilatabelakangi oleh alasan-alasan sebagaimana Quipper (2018) jelaskan, meliputi: (1) pengetahuan global, (2) akses internasional, (3) akses teknologi, (4) pergaulan internasional, (5) akses pendidikan global, (6) pendanaan internasional, dan (7) kapasitas profesional. Keseluruhan alasan tersebut mendorong generasi muda untuk menguasainya dari sistem tunggal hingga prural. Selain itu, mobilitas internasional dan arus migrasi turut memotori dan mendorong kemunculan generasi polyglot (Nurjaya:2019) yang disebabkan oleh faktor: budaya, bisnis, dan edukasi. Alhasil, dari peristiwa tersebut berdampak pada kepunahan bahasa daerah maupun bahasa nasional sebagaimana UNESCO jelaskan. Selain itu, juga terdapat faktor pendorong lain, seperti: perkawinan campur, komunikasi orang tua, dan stagnasi generasi penutur. Contoh realita kepunahan terjadi di Indonesia, dimana terdapat 652 bahasa daerah yang tersebar dari Sabang sampai Merauke hilang setiap limabelas hari sekali (Nurdiarsih:2019). Alhasil, Indonesia berada dalam situasi rentan kehilangan jati diri yang bersumber pada nilai-nilai luhur bahasa dan budaya daerah maupun nasional.

Fenomena kepunahan bahasa yang disebabkan oleh dinamika sosiolinguistik berdampak pada ketahanan sosio-budaya yang berakar dari nilai-nilai luhur bahasa dan budaya daerah maupun nasional. Situasi ini rawan terjadi pada generasi muda karena pada periode ini merupakan fase transisi yang sarat akan perubahan dalam segi emosional maupun fisik, termasuk menyangkut perkembangan bahasa. Persoalannya, bahasa remaja cenderung terpengaruh oleh tren pergaulan. Bahasa pergaulan yang dimaksud adalah bahasa populer dengan pengaruh bahasa dan budaya asing serta tatanan yang tidak sesuai dengan aturan standar bahasa. Fenomena ini merebak dikalangan muda Indonesia yang disebabkan oleh 
kemajuan teknologi dan globalisasi. Sebagai dampaknya, popularitas bahasa asing di Indonesia meningkat dan dijadikan bahasa komunikasi dalam kehidupan sehari-hari. Alhasil, dikalangan remaja Indonesia, terjadi krisis kemampuan berbahasa secara baku, yangmana dijabarkan melalui alasan-alasan berikut: (1) rendahnya kemampuan berbahasa nasional, (2) ketidaktahuannya dalam bahasa daerah, (3) kebingungannya dalam berbahasa asing, dan (4) tercampurnya bahasa nasional, daerah dan asing dalam komunikasi sehari-hari.

Masuknya bahasa maupun budaya asing dalam ruanglingkup pergaulan remaja, mengikis nilai-nilai luhur bahasa maupun budaya nasional. Bibah (2017) menjelaskan bahwa interaksi yang dibangun oleh kalangan remaja Indonesia cenderung menerapkan nilai-nilai budaya asing yang dipengaruhi oleh: (1) komunikasi secara asing dianggap lebih gaul dibanding dengan bahasa nasional ataupun bahasa daerah, (2) komunikasi secara asing lebih diterima dalam pergaulan remaja, (3) komunikasi secara asing meningkatkan kepercayaan diri remaja sebagai generasi modern. Akibatnya, remaja Indonesia kehilangan identitasnya sebagaimana terkandung dalam nilai-nilai luhur bahasa nasional maupun daerah.

Kerentanan ketahanan bahasa remaja di Indonesia menjadi tolok ukur ketahanan sosio-budaya bangsa, yangmana menyangkut lemahnya kekuatan bahasa nasional dan daerah yang tercermin dari karakter penutur aslinya. Fenomena tersebut secara umum berlaku di Indonesia, baik di kota maupun di daerah. Sebagai contoh, di wilayah Banyumas dimana wilayah tersebut merupakan bagian dari wilayah Jawa Tengah yang bercirikan bahasa Jawa sebagai bahasa utamanya mulai memudar dikalangan pemuda Jawa. Gambaran tersebut nampak di SMA Negeri 4 Purwokerto, yangmana siswa/siswinya cenderung berminat pada bahasa Asing, khususnya bahasa Inggris dan bahasa Prancis. Sebagai konsekwensinya, bahasa Jawa mulai ditinggalkan dan hanya bersifat matapelajaran muatan lokal, sedangkan minat terhadap bahasa Indonesia dirasa menurun. Situasi tersebut ternyata berlaku berbeda di negara Prancis maupun di kawasan Frankofon yang secara sosio-kultural memiliki karakter sama dengan Indonesia sebagai bangsa multirasial dan multikultural. Prancis dan kawasan Frankofon mengakomodir seluruh perbedaan dalam kemanunggalan bahasa berkat politik monolinguistiknya. Politik tersebut merujuk pada politik bahasa yang berakar dari kesepakatan bersama dengan mempertimbangkan keterkaitannya pada ranah kehidupan sosial, nasional dan internasional. Godet (2009) menjelaskan tujuan utama politik monolinguistik, meliputi: orientasi penutur pada keterikatan budaya asli, terutama terhadap nilai dan norma, serta menyangkut solidaritas sosial dan kebersamaan yang merujuk pada sikap nasionalisme, dan mempromosikan stabilitas linguistik sebagai jaminan stabilitas nasional. Singkatnya, konsep monolinguistik Prancis dijabarkan melalui upaya-upaya nyata, meliputi: (1) ikatan penutur dengan orisinalitas budaya, (2) sikap berbahasa bersumber dari nilai dan norma, (3) solidaritas dan kebersaamaan antar etnis maupun ras berbasis bahasa, (4) stabilitas linguistik sebagai media komunikasi nasional, (5) standarisasi bahasa sesuai kepribadian bangsa, (6) standar kompetensi bahasa bagi penutur asli maupun asing, (7) peran lembaga sensor bahasa, (8) penghormatan dan toleransi terhadap bahasa dan budaya lain, (9) jaminan keberlangsungan dan pengembangan bahasa lain, serta (10) harmonisasi sosial dan kemanusian dalam bahasa.

Berpijak dari konsep monolinguistik Prancis yang mampu menyatukan perbedaan latarbelakang penuturnya dalam kemanunggalan bahasa, tentunya layak untuk dijadikan model pembinaan sosio-budaya di Indonesia, khususnya bagi kalangan remaja mencakup konteks berbahasa daerah maupun nasional. Melalui latarbelakang dan permasalahan yang ada, dapat disimpulkan tujuan pemberdayaan masyarakat ini terfokus pada upaya pembinaan ketahanan sosio-budaya remaja dalam ranah bahasa berkaca dari model monolinguistik Prancis.

\section{METODE PELAKSANAAN}


Fokus program pembinaan ketahanan bahasa dan budaya nasional sebagai ciri atau identitas remaja Indonesia dapat terlaksana dengan menerapkan metode: (1) diskusi yang secara umum digunakan dalam proses pembelajaran dengan mengajak siswa dan guru untuk memecahkan problematika pembelajaran bahasa, (2) tanya jawab yang secara umum menekankan aspek tanggapan pemelajar terkait dengan pengetahuan bahasa dan budaya Prancis secara umum, maupun yang relevan dengan budaya nasional, (3) demontrasi dengan memperagakan kepada siswa dan siswi, maupun guru terkait kompetensi bahasa dan budaya Prancis yang relevan diadopsi oleh pemelajar bahasa asing, (4) latihan dengan fokus berlatih bahasa sesuai dengan kaidahnya, (5) evaluasi melalui pre-test dilakukan sebelum memasuki program dan post-test yang diberikan setelah pendampingan dalam rangka mengukur efektivitas model.

\section{HASIL DAN PEMBAHASAN}

Program pemberdayaan masyarakat dengan fokus utama pembinaan ketahanan sosio-budaya remaja melalui sistem monolinguistik Prancis merupakan langkah awal dalam menyikapi ancaman ketahanan bahasa nasional dan bahasa daerah, yang disebabkan oleh pengaruh bahasa dan budaya asing dalam kehidupan remaja saat ini. Dalam rangka membenahi cara pandang dan kerawanan kecintaan mereka terhadap bahasa nasional, maka ada beberapa langkah awal pelaksanaan program, diantaranya : (1) observasi kelas pembelajaran bahasa, meliputi: bahasa Prancis, bahasa Inggris, bahasa Indonesia, dan bahasa daerah di kelas XII SMA Negeri 4 Purwokerto, (2) wawancara kepada seluruh guru pengampu matapelajaran bahasa, wakil kepala sekolah bidang kurikulum, wakil kepala sekolah bidang kesiswaan, dan kepala sekolah terkait mekanisme pembelajaran bahasa di sekolah tersebut, meliputi :

Tabel 1. Rekap Pembelajaran Bahasa di SMA Negeri 4 Purwokerto

\begin{tabular}{|c|c|c|c|c|c|}
\hline \multirow{2}{*}{ No. } & \multirow{2}{*}{ Pembelajaran } & \multicolumn{4}{|c|}{ Mata Pelajaran Bahasa } \\
\hline & & Daerah & Indonesia & Inggris & Prancis \\
\hline 1. & Tujuan & $\begin{array}{l}\text { Melestarikan } \\
\text { bahasa dan } \\
\text { budaya lokal }\end{array}$ & $\begin{array}{l}\text { Meningkatkan } \\
\text { kemampuan } \\
\text { berkomunikasi } \\
\text { dengan baik dan } \\
\text { benar, lisan } \\
\text { maupun tulisan, } \\
\text { serta } \\
\text { menumbuhkan } \\
\text { apresiasi } \\
\text { terhadap } \\
\text { kesastraan } \\
\text { Indonesia. }\end{array}$ & $\begin{array}{l}\text { Mengembangkan } \\
\text { kemampuan } \\
\text { berkomunikasi dalam } \\
\text { bahasa Inggris } \\
\text { mencakup lisan dan } \\
\text { tulisan, } \\
\text { Menumbuhkan } \\
\text { kesadaran akan hakekat } \\
\text { dan pentingnya bahasa } \\
\text { tersebut, } \\
\text { Mengembangkan } \\
\text { pemahaman keterkaitan } \\
\text { antara bahasa dan } \\
\text { budaya serta } \\
\text { memperluas cakrawala } \\
\text { budaya. }\end{array}$ & $\begin{array}{l}\text { Mengoptimalkan } \\
\text { pengembangan } \\
\text { peserta didik dalam } \\
\text { bidang komunikasi, } \\
\text { ilmu pengetahuan, } \\
\text { teknologi, dan seni. }\end{array}$ \\
\hline 2. & Strategi & $\begin{array}{l}\text { Tatap muka, } \\
\text { pemberian } \\
\text { materi, } \\
\text { penugasa, }\end{array}$ & $\begin{array}{l}\text { Tatap muka, } \\
\text { pemberian } \\
\text { materi, } \\
\text { penugasan, }\end{array}$ & $\begin{array}{l}\text { Tatap muka, } \\
\text { pemberian materi, dan } \\
\text { penugasan. }\end{array}$ & $\begin{array}{l}\text { Tatap muka, } \\
\text { pemberian materi, } \\
\text { penugasan, }\end{array}$ \\
\hline 3. & Orientasi & $\begin{array}{l}\text { Meningkatkan } \\
\text { pengetahuan } \\
\text { dan }\end{array}$ & $\begin{array}{l}\text { Meningkatkan } \\
\text { kemampuan } \\
\text { komunikasi }\end{array}$ & $\begin{array}{l}\text { Mengembangkan } \\
\text { kemampuan } \\
\text { berkomunikasi }\end{array}$ & $\begin{array}{l}\text { Mengoptimalisasi } \\
\text { pengembangan } \\
\text { SDM dalam bidang }\end{array}$ \\
\hline
\end{tabular}




\begin{tabular}{|c|c|c|c|c|c|}
\hline & & $\begin{array}{l}\text { keterampilan } \\
\text { berbahasa dan } \\
\text { budaya daerah }\end{array}$ & $\begin{array}{l}\text { lisan dan } \\
\text { tulisan, serta } \\
\text { menumbuhkan } \\
\text { apresiasi } \\
\text { terhadap karya } \\
\text { sastra. }\end{array}$ & $\begin{array}{l}\text { mencakup lisan dan } \\
\text { tulisan, serta } \\
\text { menumbuhkan hakekat } \\
\text { dan pentingnya bahasa } \\
\text { tersebut dalam } \\
\text { komunikasi global }\end{array}$ & $\begin{array}{l}\text { komunikasi, IPTEK } \\
\text { dan seni }\end{array}$ \\
\hline 4. & Model & Klasikal & Klasikal & Klasikal & Klasikal \\
\hline 5. & Materi & Modul & Modul & Modul & Modul \\
\hline 6. & Hasil & Nilai & Nilai & Nilai & $\begin{array}{l}\text { Nilai mengacu pada } \\
\text { hasil sertifikasi } \\
(D E L F)\end{array}$ \\
\hline
\end{tabular}

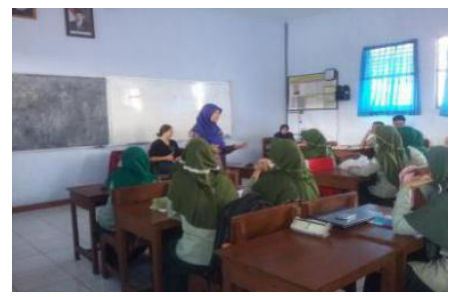

Perkenalan Tim dengan Siswa/Siswi Kelas XII

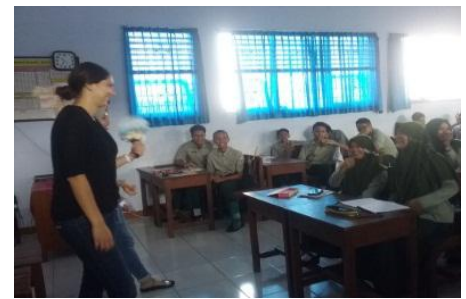

Presentasi Penutur Prancis di Kelas XII

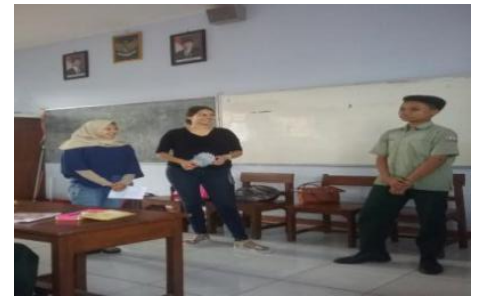

Kegiatan Interaktif Antara Penutur Bahasa Prancis dengan Siswa/Siswi kelas XII

Gambar 1. Dokumentasi Observasi Kelas Berbahasa di SMA Negeri 4 Purwokerto

Pre-test terdiri atas: (10) soal terkait pembelajaran bahasa, (10) soal terkait dengan nasionalisme kebahasaan, (10) soal terkait dengan kontribusi bahasa Prancis secara umum, (10) soal terkait dengan kontribusi bahasa Prancis dalam memupuk identitas nasional remaja, dan (10) soal terkait dengan idealisme remaja dalam mempelajari bahasa. Beberapa contoh soal yang diangkat dalam pre-test adalah bahasa yang disukai, jenis bahasa yang meningkatkan kualitas hidup, bahasa yang mengedepankan etika dan sopan santun, serta keinginan pemelajar dalam mempelajari bahasa asing. Hasilnya, dari seluruh angket yang diberikan menunjukkan bahwa bahasa asing menjadi orientasi utama dalam kehidupan sehari-hari.

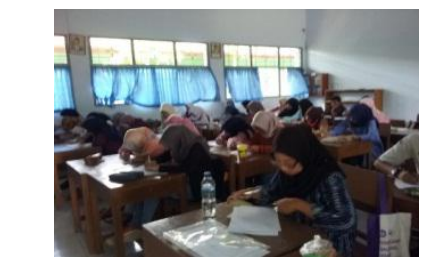

Pre-test kelas XII IPA2

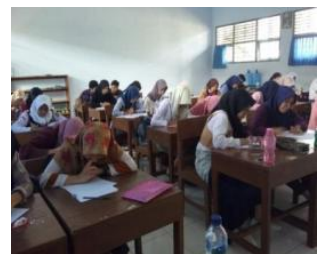

Pre-test kelas XII IPA 4

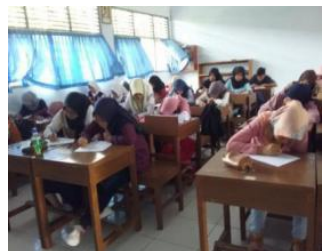

Pre-test kelas XII IPS 2

Gambar 2. Dokumentasi Pre-Test Kelas Berbahasa di SMA Negeri 4 Purwokerto

Berpijak dari hasil observasi dan pre-test, tahap pembinaaan meliputi : (1) Uraian Konsep Monolinguisme Prancis berupa paparan esensi peran dan fungsi bahasa Prancis dalam pembangunan peradaban, sebagaimana telah dijelaskan dalam teori bahwa bahasa Prancis bukanlah sekedar pengetahuan bahasa dan budaya, tetapi fokusnya adalah membudayakan manusia "langue civilisatrice" dalam keberagaman sepertihalnya kata "S'il vous plaitt!" untuk meminta bantuan, membeli sesuatu, memesan sesuatu, menanyakan 
sesuatu, dan memohon ijin, memberi gambaran bahwa dalam hal apapun, etika menjadi bagian utama dalam bahasa Prancis. Oleh sebab itu perlu adanya pembiasaan etika dalam berbahasa seperti kalimat "Je voudrais..." yang menjelaskan derajat bahasa. Kemudian konsep menghormati, yangmana konteks ini sedikit berbeda dengan konteks Indonesia, seperti "Vous" dan "Tu" bukan berarti perbedaan status atau derajat sosial, namun menekankan kontekstual komunikasi.
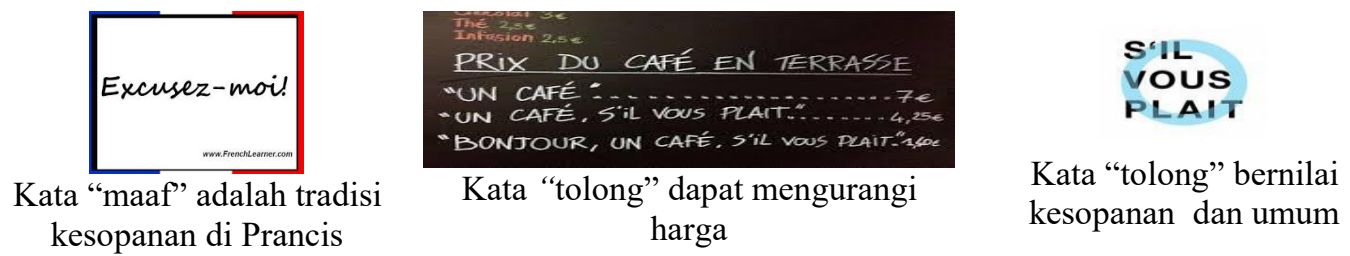

Gambar 3. Konsep Monolinguisme Prancis

(2) Relevansi Konsep Monolinguisme Prancis dalam Bahasa Nasional, melalui upaya peralihan kode bahasa. Maksudnya, salah satu strategi penguatan bahasa Prancis sebagai bahasa tunggal melalui sosialisasi istilah-istilah asing yang dirubah kedalam bahasa Prancis, sebagaimana dijabarkan dalam tabel berikut ini :

Tabel 2. Contoh Perubahan Kosa Kata Asing kedalam Bahasa Prancis

\begin{tabular}{cccc}
\hline No. & \multicolumn{2}{c}{ Kata } & Populer di Indonesia \\
\cline { 2 - 3 } & Kosa-Kata Asing & Prancis & \\
\hline 1. & Handphone & Portable & HP/Telephon genggam \\
2. & Email & Coureil & Email/Surel \\
3. & Camera & Appareil & Kamera \\
4. & Week-end & la fin de la semaine & Week-end/akhir pekan \\
5. & Fashion & Haut-Couture & Fashion/Adi busana \\
\hline
\end{tabular}

(3) Esensi Monolingisme Prancis dalam Seni Berfikir dan Seni Berperilaku, meliputi: nilai-nilai solidaritas, universalitas, disiplin, cermat, hemat, estetika dan etika dalam kriteria penilaian Diplôme d'Étude en Langue Français (DELF) atau standar penguasaan bahasa Prancis internasional dan seumur hidup, mencakup kriteria: (a) memahami dan mematuhi petunjuk yang diminta dari sebuah teks penugasan yang bersensi : kecerdasan, kepatuhan, dan ketepatan, (2) memilih subyek yang tepat berdasarkan konteks, bukan strata sosial yang beresensi: adaptif, sopan-santun, fleksibel, dan kesetaraan, (3)mengkalkulasi jumlah penggunaan kata dalam menjawab teks penugasan yang beresensi: ekonomis, prioritas, dan efisien, (4) memilih kata-kata yang sesuai dengan subyek berdasarkan konteks yang beresensi: ketepatan, kecerdasan, dan efektif, (5) mampu menjelaskan informasi secara jelas dan efektif yang bersensi: informatif, terstruktur, dan efisien, (6) mampu menggunakan kata-kata tepat yang beresensi: efektif dan tepat, (7) mampu membentuk kata atau kalimat dari masing-masing unsur, meliputi: kata kerja, kata sifat, kata benda, dan kata keterangan yang berensi: kecerdasan dan logika matematis, dan (8) mampu menghubungkan kata dengan kata menjadi kalimat, dan kalimat dengan kalimat menjadi paragraf secara koheren dan logis yang beresensi : efektif, logis, terstruktur, dan koheren.

\author{
Contoh Penugasan 1 \\ Consigne Production Écrite DELF A1 Scolaire
}


Petunjuk Kompetensi Menulis DELF A1 untuk Anak Sekolah

Vous vivez dans un pays francophone. Vous écrivez à votre professeur de français. Vous lui dites où vous habitez et vous racontez ce que vous faites (travail, études, loisirs, etc.). (40 minimum)

Anda hidup di sebuah negara frankofon. Anda menulis surat kepada guru bahasa Prancis. Anda mengatakan padanya dimana Anda tinggal dan Anda menceritakan apa yang Anda lakukan (pekerjaan, sekolah, waktu luang, dsb). (minim 40 kata)

Berlandaskan esensi monolinguisme Prancis sebagaimana telah dijabarkan diatas, maka dalam hal penugasan, penutur bahasa Prancis akan : (1) memperhatikan jumlah kata penugasan (perhitungan), (2) memahami kata-kata kunci dari masing masing kalimat penugasan, yaitu: (verbe: vivre, ecrire, dire, habiter, raconter, et faire), (nom : francophone, professeur, l'addresse, les activités: travail,études, loisirs), (3) memahami tipe tugas : surat resmi, (4) memahami sasaran komunikasi : votre professeur, yang menunjuk pada konsep formal, (5) memahami latar tempat : negara atau kota Frankofon.

\section{Contoh Penugasan 2 \\ Consigne Production Écrite DELF A1 Publique \\ Petunjuk Menulis DELF A1 untuk Umum}

Vous venez de vous installer en France pour vos études. Vous allez rester six mois. Vous écrivez un courriel à votre ami(e) pour lui raconter votre installation. Vous lui expliquez ce que vous faites et vous lui demandez de ses nouvelles (40 à 50 mots).

Anda tiba di Prancis dan Anda tinggal di sana untuk studi, Anda akan tinggal selama enam bulan. Anda menulis email kepada rekan laki-laki atau rekan perempuan Anda untuk menceritakan padanya mengenai tinggal Anda. Anda menjelaskan kepadanya apa yang Anda lakukan disana dan Anda bertanya perihal kabarnya. (40 hingga 50 kata).

Penyelesaian penugasan berikutnya adalah : (1)memperhatikan jumlah kata yang dibatasi antara 40 hingga $50 \mathrm{kata}$, artinya penutur memahami apabila kalimatnya kurang dari 40 atau lebih dari 50 kata maka nilainya akan berkurang, dalam hal ini terpadat toleransi 10\% kelebihan kata, lebih dari itu merugikan penuturnya, (2) memahami kata-kata kunci dari masing-masing kalimat penugasan, yaitu: (verbe: installer, rester, écrire, raconter, faire, demander), (nom: études, six mois, ami, installation, activités, et nouvelles), (3) memahami tipe tugas: memahami bentuk/bagian-bagian dari struktur sureil, serta membuatnya, (4) memahami sasaran komunikasi: teman Anda (informal atau kekeluargaan), (5)memahami latar tempat : kota-kota di Prancis.

Contoh penugasan-penugasan di atas, mula-mula diberikan kepada siswa/siswi untuk amati dan dikerjakan. Pada awalnya, hal yang dilakukan oleh siswa/siswi adalah mengerjakan dengan cara konvensional sebagaimana menunjukkan seni berfikir dan seni berperilaku orang Indonesia, yaitu merespon secara umum sebuah penugasan, seperti :

Contoh 3

Jawaban Penugasan 1 Mengikuti Alur Berfikir Indonesia 


\section{Bonjour Monsieur Jean,}

Maintenant, je suis à Paris, je travaille à la banque, j'étude économie, et mange beaucoup des nourritures spéciales comme : ratatouille, fois-gras, et cordon bleu. J'aime voyager beaucoup pendant le week-end. Et comment allez-vous ?

Merci,

Stéphanie

Bonjour Monsieur Jean,

Paris, le 10 octobre 2019

Comment allez-vous?

Je souhaite que vous allez-bien. Maintenant je vive à Paris et je travaille à la banque internationale. Pendant la fin de la semaine, j'étude économie dans une école supérieur pour perfectionner ma compétence professionnelle. S'il y a un temps libre, j'aime voyager et j'aime gouter la nourriture spéciale, comme : ratatouille, fois-gras, et cordon bleu au restaurant. Alors, je visite beaucoup de site touristique là-bas.

Cordialement,

Stéphanie

Merujuk pada jawaban penugasan mengikuti alur berfikir Indonesia dan Prancis terdapat beberapa perbedaan mendasar, yangmana muncul dari jawaban. Perbedaan pertama terletak pada pemahaman petunjuk/consigne untuk menentukan bentuk penugasan. Dalam tradisi Indonesia, fokus penugasan membentuk pengetahuan global, contohnya dalam bentuk wujud tulisan yang berupa tulisan diskriptif, sedangkan dalam tradisi Prancis petunjuk/consigne mengorientasikan penugasan pada pemahaman detail, berupa bentuk surat resmi beserta salam pembuka dan salam penutup yang tepat. Perbedaan kedua, merujuk pada koherensi dan kohesi antar kalimat, dalam tradisi Indonesia kata penghubung dan/et biasa digunakan, namun dalam tradisi Prancis konjungsi mutlak dalam komunikasi selain dan/et adalah jadi/alors sebagai sarat kesimpulan. Perbedaan ketiga, terletak pada keterangan tempat dan waktu. Bagi masyarakat Indonesia waktu dan tempat bukanlah aspek utama dibandingkan dengan isi, sedangkan di Prancis tempat dan waktu tidak kalah penting dibandingkan dengan isi.

Fenomena di atas merepresentasikan cara pandang berbeda dalam menyelesaikan problematika, baik menyangkut problematika artifisial maupun problematika reel. Maksudnya, problematika artifisial terkait dengan persoalan-persoalan pembelajaran, sedangkan problematika reel menyangkut persoalan kehidupan. Hal ini berasosiasi dengan tradisi berfikir yangmana setiap bangsa memiliki cara masing-masing. Di Indonesia, tradisi berfikir diorientasikan pada hasil dengan langkah-langkah yang menyesuaikan, namun di Prancis tradisi berfikir diorientasikan pada proses serta langkah-langkah yang diambil. Fakta ini muncul dari model penugasan dalam bahasa Indonesia yang biasa dijumpai, seperti contoh berikut ini:

Contoh 4

Bentuk-Bentuk Penugasan dalam Materi Bahasa Indonesia Untuk Penutur Asing (BIPA) Tingkat Pemula

(Muliastuti, 2016:63)

Tulislah cerita tentang hobimu seperti cerita di bawah ini! 
Tulislah kartu ucapan untuk temanmu!

Bentuk penugasan dalam bahasa Indonesia menunjukkan nilai-nilai berbeda dengan konsep penugasan bahasa Prancis, yangmana tidak ada detail nilai-nilai karakter yang dibangun. Dalam hal ini bentuk penugasan bersifat perintah, dibangun dalam kalimat singkat dan sederhana, serta kriteria penilaian yang hanya terfokus pada aspek kebahasaan. Sedangkan dalam bentuk penugasan bahasa Prancis, konsep berupa kalimat informatif, detail, sederhana, namun terdapat indikator-indikator penilaian non-bahasa, sepertihalnya: kecerdasan, kecermatan, managerial, dan penghargaan. Singkatnya, dari pola-pola penugasan ini dapat disimpulkan mengenai pola pikir bangsa yang tercermin dalam konsep kebahasaan.

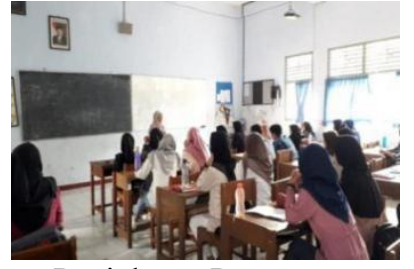

Penjelasan Penugasan

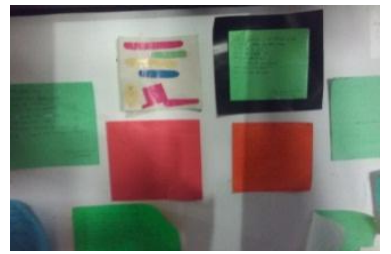

Hasil Penugasan

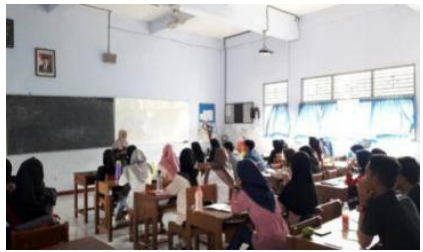

Pembahasan Penugasan

Gambar 4. Dokumentasi Kegiatan Penugasan

Tahapan selanjutnya adalah tahap inti, meliputi tahapanan : (a) Pembiasaan pertama menyangkut subyek "Aku" dalam segala situasi diganti dengan subyek "Saya" dan "Kulo/Kawulo" dalam bahasa Jawa. (a) Pembiasaan ke-dua meliputi optimalisasi kebiasaan bertutur dalam bahasa Indonesia: (tolong, mohon maaf, terimakasih, dan permisi), maupun bahasa daerah, dalam hal ini bahasa daerah yang dipelajari adalah bahasa Jawa /(nyuwun tulung, nuwun sewu, maturnuwun, derek langkung), (c) Pembiasaan ke-tiga, menyangkut kedisiplinan waktu yang diterapkan dalam kegiatan penugasan maupun kegiatan sehari-hari, (d) Pembiasaan ke-empat meliputi penugasan yang meningkatkan kreativitas dan inovasi berbahasa dengan tujuan akhirnya pada kesuksesan pribadi yang percaya diri dan mereduksi sikap-sikap plagiarisme, (e) Pembiasaan ke-lima meliputi penghormatan dan penghargaan terhadap karya orang lain ataupun karya sendiri melalui pemberian ucapan selamat, seperti :

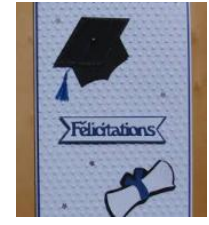

Ucapan

Selamat

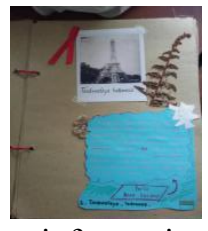

informasi replika Eiffel

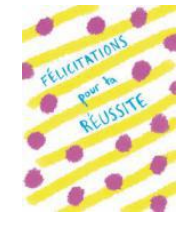

Ucapan

Selamat

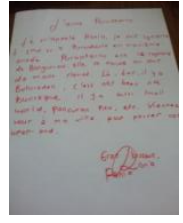

Diskripsi

Baturaden
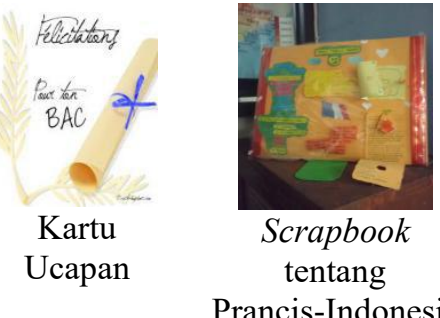

Gambar 5.Dokumentasi Apresiasi Karya-Karya Siswa/Siswi dalam Praktek Bahasa Prancis

(f) Pembiasaan ke-enam meliputi: keberagaman etnis, ras, bahasa dan budaya, yangmana esensi dari konsep monolingisme Prancis adalah pemahaman antarbudaya. Konteks ini, mengarahkan pada interaksi nyata generasi muda dengan penutur asli Prancis untuk turut berbagi wawasan pentingnya peran anak muda dalam menjaga warisan bahasa dan budaya nasional dengan kompetensi global. 


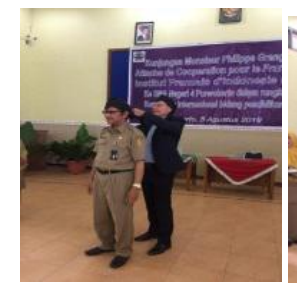

Tanda

Persahabatan

Kepala Sekolah dengan Attase

Linguistik

Prancis

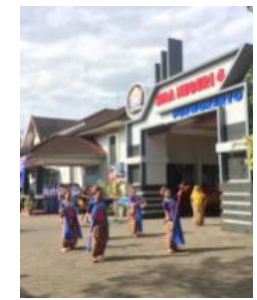

Tarian

Kentongan

untuk

menyambut

tamu Prancis

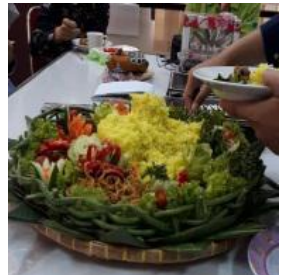

Jamuan Makan

Untuk Tamu

Prancis

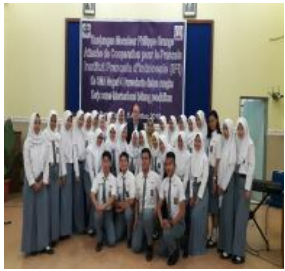

Foto Bersama

Bapak Attase

Linguistik Prancis dengan

siswa/siswi SMA 4

Purwokerto

Gambar 6. Dokumentasi Kegiatan Pemahaman Antar-Budaya di SMA Negeri 4 Purwokerto

Akhirnya, tahapan ini diuji efektivitasnya melalui Post-Test dengan materi yang diujikan sama dengan pre-test meliputi: (10) soal terkait pembelajaran bahasa, (10) soal nasionalisme kebahasaan, (10) soal terkait kontribusi bahasa Prancis secara umum, (10) soal terkait dengan kontribusi bahasa Prancis dalam memupuk identitas nasional remaja, dan (10) butir soal terkait dengan idealisme remaja dalam mempelajari bahasa asing.

\section{KESIMPULAN}

Kesimpulan dari program ini terdapat perubahan pemahaman, kebiasaan dan orientasi warga sekolah SMA Negeri 4 Purwokerto menyangkut peran dan fungsi pembelajaran bahasa daerah, bahasa nasional, dan bahasa asing dalam membangun identitas mereka, terutama siswa/siswinya sebagai generasi muda Indonesia. Pada awalnya minat terhadap bahasa nasional dan bahasa daerah menurun akibat terpengaruh oleh pandangan modern yang memarjinalkan bahasa nasional dan bahasa daerah, dan menjadikan bahasa asing sebagai unsur utama. Namun melalui implementasi model molinguistik Prancis yang sarat akan etika dan moral bersumber dari budaya asli, serta menyangkut solidaritas sosial, nasionalisme, dan jaminan stabilitas nasional, terdapat perubahan mendasar terkait pemahaman, orientasi, dan kebanggaan bahasa asing bagi perkembangan identitasnya. Pada awalnya siswa/siswi berfikir bahwa bahasa asing sangatlah penting dalam mendukung kesuksesan, kemudian setelah diadakan program pembinaan pemahaman, tujuan, dan orientasi mereka berubah menjadi bangga berkomunikasi dengan bahasa daerah dan bahasa nasional, dan mampu mengkomunikasikan nilai-nilai luhur bahasa dan budaya lokal maupun nasional dalam kancah internasional berbasis bahasa asing. Akhirnya, program pembinaan ketahanan sosio-budaya remaja melalui model monolinguistik Prancis mampu mengorientasikan peran dan fungsi bahasa Asing, tanpa mereduksi nilai-nilai luhur bahasa dan budaya nasional maupun lokal sebagai cerminan bangsa Indonesia. Dengan program ini diharapkan adanya program lanjutan berupa upaya eliminasi gegar budaya pada masyarakat multilingual dan multikultural, khususnya bagi generasi muda sebagaimana berpijak pada situasi Indonesia saat ini yang dihadapkan pada keberagaman.

\section{UCAPAN TERIMAKASIH}

Program Pemberdayaan Masyarakat dengan tajuk "Upaya Pembinaan Ketahanan Sosio-Budaya Remaja Indonesia Melalui Model Monolinguistik Prancis di SMA Negeri 4 
Purwokerto" dapat terlaksana dengan baik berkat adanya bantuan dan partisipasi dari berbagai pihak, diantaranya :

1. Lembaga Penelitian dan Pengabdian Masyarakat (LPPM) Universitas Jenderal Soedirman (UNSOED),

2. Institut Français Indonesia (IFI) selaku mitra pengembangan bahasa Prancis di Indonesia,

3. SMA Negeri 4 Purwokerto selaku mitra Program Pemberdayaan Masyarakat (PPM) Riset, dan

4. Pihak-Pihak lain yang terlibat.

\section{DAFTAR PUSTAKA}

Anak UI.Com (14 Maret 2015) 5 Bahasa Asing yang Dipelajari Orang Indonesia. Dalam https://www.anakui.com/5-bahasa-asing-yang-banyak-dipelajari-orang-indonesia/\#. Xb4vEeYzbIU. Diakses pada tanggal 21 Oktober 2019, pukul 12.00 WIB

Asiati, Tri (2018) Adaptasi Model Monolingustik Prancis dan Eksistensi Lembaga Budaya dalam Meningkatkan Ketahanan Lingua Franka. Dalam Jurnal Ketahanan Nasional Vol 4, ed 2018. Yogyakarta: UGM Press.

(2018) Le Rôle des Résaux Culturels Officiels au Sein de la Diplomatie Culturelle Française à la Région Banyumas. Dalam Prosiding Seminar Internasional le Français III, page 24-29. Yogyakarta : UGM Press.

(2018) Monolinguistik Prancis dan Eksistensi Lembaga Budaya dalam Pengembangan Bahasa Indonesia sebagai Lingua Franka. Dalam Buku Program Seminar Nasional "Pengembangan Sumber Daya Perdesaan dan Kearifan Lokal Berkelanjutan VIII, hlm:186. Purwokerto: LPPM UNSOED

Ayu, Rindang (29 September 2019). Mengenal Empat Kecerdasan Manusia (IQ, EQ, SQ, dan TQ). Dalam Kompasiana: https://www.kompasiana.com/rindangayu/5d90d51509 7f364a480dba23/mengenal-empat-kecerdasan-manusia-iq-eq-sq-dan-tq?page=all.

Diakses pada tanggal 21 Oktober 2019, pukul 12.00 WIB

Bibah, Habibah (30 Desember 2017) Pengaruh Bahasa Asing Untuk Para Generasi Muda. Diakses dalam https://www.kompasiana.com/habibahbibah/5a471df4bde5752bf1 47a5e4/pengaruh-bahasa-asing-untuk-para-generasi-muda, pada tanggal 12 November 2018, pukul 15.00 WIB

GODET, Natacha (2015) La Langue Française. Dalam http://origines66.fr/wp-content/uploads/2015/11/La-Langue-Francaise-2009.pdf.

Diakses pada tanggal 29 September 2019, pukul 20.00 WIB

Jessica (26 Agustus 2017). Benarkah Anak Bilingual dan Multilingual Lebih Cerdas. Dalam https://www.educenter.id/benarkah-anak-bilingual-dan-multilingual-lebih-cerdas/.

Diakses pada tanggal 12 September 2019, pukul 12.00 WIB.

Muliastuti, Liliana, dkk (2016). Sahabatku Indonesia. Jakarta : Badan Pengembangan dan Pembinaan Bahasa Kementerian Pendidikan dan Kebudayaan.

Nurdiarsih, Fadjriah (19 April 2019). UNESCO Ungkap Bahasa Daerah di Indonesia Punah Setiap 15 Hari Sekali. Dalam Liputan 6 https://www.liputan6.com/news/read/ 3469714/unesco-ungkap-bahasa-daerah-di-indonesia-punah-setiap-15-hari-sekali.

Diakses pada tanggal 21 Oktober 2019, pukul 12.00 WIB

Nurjaya (6 Januari 2019). Poligot Penjelasan dan Contoh Penggunaannya. Dalam https://www.kampunginggris.id/polygot-penjelasan-dan-contoh-penggunaannya/.

Diakses pada tanggal 21 Oktober 2019, pukul 12.00 
Quipper (6 Agustus 2018). 7 Alasan Penting Kamu Harus Belajar Bahasa Asing. Dalam https://www.quipper.com/id/blog/quipper-campus/campus-life/7-alasan-penting-kena pa-belajar-bahasa-asing/. Diakses pada tanggal 21 Oktober 2019, puku 12.00 WIB 